\title{
ANALISIS SENTIMENT CYBERBULLYING PADA SOSIAL MEDIA TWITTER MENGGUNAKAN METODE SUPPORT VECTOR MACHINE
}

\author{
Muh. Fitra Rizki, Karina Auliasari, Renaldi Primaswara Prasetya \\ Program Studi Teknik Informatika S1, Fakultas Teknologi Industri \\ Institut Teknologi Nasional Malang, Jalan Raya Karanglo km 2 Malang, Indonesia \\ 1718053@scholar.itn.ac.id
}

\begin{abstract}
ABSTRAK
Twitter merupakan salah satu media sosial yang saat ini menjadi trend, karena terdapat banyak sekali berita dan informasi yang yang dapat direspon dengan cepat dan tepat dari berbagai sudut pandang. Hal ini menjadikan Twitter tidak hanya berdampak positif, tetapi juga berdampak negatif bagi pengguna maupun non-pengguna Twitter, salah satunya adalah cyberbullying. Cyberbullying adalah bentuk intimidasi yang pelaku lakukan untuk melecehkan korbannya melalui perangkat teknologi. Korban yang mengalami Cyberbullying akan mengalami gangguan fisik hingga psikologis seperti kesepian, kegelisahan, depresi yang lebih tinggi, dan merasa hargadirinya rendah. Selain itu korban yang mengalami Cyberbullying juga akan merasakan tekanan sehingga menunjukkan keinginan bunuh diri yang lebih tinggi. Pada penelitian ini dilakukan proses analisis sentiment cyberbullying yang disampaikan oleh pengguna pada media sosial twitter dengan mengembangkan sistem berbasis web untuk mengklasifikasikan sentiment tersebut menggunakan metode support vector machine. Data inputan pada sistem ini berupa konten tweet yang diperoleh dari twitter dengan memasukkan keyword hashtag yang berpotensi menimbulkan cyberbullying seperti \#cebong atau \#kadrun dan tidak melebihi 100 data tweet. Sedangkan outputnya berupa klasifikasi sentiment cyberbullying atau non-cyberbullying dari setiap tweet yang sudah melewati proses text preprocessing dan pembobotan teks dengan TF-IDF. Dari hasil pengujian menunjukan dengan menggunakan 100 data tweet, sistem mampu melakukan proses klasifikasi dengan rata-rata waktu 101100,2 milisecond dan kecepatan pemrosesan 0,000989 data per milisecond. Diperoleh pula hasil pengukuran evaluasi klasifikasi dengan menggunakan metode confusion matrix dengan nilai recall $64 \%$, precision 58\% dan tingkat accuracy sebesar $70 \%$.
\end{abstract}

Kata Kunci: Support Vector machine, Analisis Sentiment, cyberbullying, Text Preprocessing, Term FrequencyInverse Document Frequency

\section{PENDAHULUAN}

Media sosial adalah platform media yang berfokus pada kehadiran pengguna dan mempromosikan aktivitas dan kolaborasi mereka. Oleh karena itu, media sosial dapat dikatakan sebagai media online yang dapat mempererat hubungan antara pengguna dan koneksi sosial. Twitter merupakan salah satu media sosial yang saat ini selalu menjadi pusat trending di Indonesia, karena terdapat banyak sekali informasi yang yang dapat direspon dengan cepat dan tepat dari berbagai sudut pandang. Hal ini menjadikan Twitter tidak hanya berdampak positif, tetapi juga berdampak negatif bagi pengguna maupun non-pengguna Twitter, salah satunya adalah cyberbullying.

Data Kasus cyberbullying di Indonesia saat ini masih sulit ditemukan secara menyeluruh pada platform media sosial twitter ini. Namun baru-baru ini pemerintah Indonesia berkerjasama dengan POLRI tertanggal 24 februari 2021 telah meresmikan beroperasinya polisi virtual yang bertugas melakukan pelacakan dan memberikan peringatan kepada pengguna yang mengunggah postingam baik berupa text ataupun gambar yang berpotensi melanggar pidana pada UU ITE. Upaya yang dilakukan oleh Twitter dalam menangani cyberbullying diantaranya yaitu pembatasan reply, rethink method, pemblokiran, mute dan pelaporan akun. Namun, fitur - fitur tersebut belum dapat mengklasifikasikan ke dalam tipikal kalimat atau kata yang mengandung cyberbullying atau Non-Cyberbullying.

Berdasarkan permasalahan yang diuraikan diatas tersebut, maka dibutuhkan adanya analisis sentimen untuk mengklasifikasikan tweet yang mengandung unsur cyberbullying atau Non-Cyberbullying. Sistem yang akan dibuat berbasis web dengan menggunakan metode klasisfikasi dari Sentiment Analylis dengan algoritma Support Vector machine (SVM). Sehingga dengan adanya sistem ini nantinya diharapkan dapat membantu kinerja polisi virtual POLRI ini dalam mengidentifikasi tweet yang berpotensi melanggar pidana UU ITE tersebut dan secara tidak langsung akan meminimalisir pengguna untuk membuat konten Twitter yang mengandung unsur cyberbullying.

\section{TINJAUAN PUSTAKA}

\subsection{Penelitian Terdahulu}

Beberapa penelitian terkait analisis sentiment, diantaranya dilakukan oleh Maria Mega Mala Olhang, Sentot Achmadi dan F.X Ariwibisono. di tahun 2020 yaitu mengembangkan analisis sentimen pengguna twitter terhadap COVID-19 di Indonesia menggunakan metode Naive Bayes Classifier (NBC). Pada penelitian ini, dilakukan proses menganalisis 
sentimen masyarakat terhadap aspirasi yang disampaikan melalui twitter dengan memasukkan keyword seperti \#coronavirusindonesia atau \#covid19 dengan jumlah data tidak melebihi 500 data tweet. Dari hasil penelitian tersebut menunjukkan hasil tingkat akurasi yang didapatkan dengan melakukan pengujian terhadap 75 dokumen tweet adalah pengukuran akurasi recall $32 \%$, precisson $80 \%$, FMeasure $45 \%$ serta rata-rata akurasi 36\% [1].

Ditahun yang sama, Amar P. Natasuwarna juga melakukan penelitian tentang analisis sentimen yaitu seleksi fitur Support Vector Machine pada keberlanjutan pembelajaran daring. Tahapan penelitian terdiri dari pengambilan data mentah, preprocessing data, seleksi fitur dengan Term Frequency dan TF-IDF, klasifikasi dengan Support Vector Machine (SVM), dan evaluasi menggunakan k-Fold Cross Validation dan Confusion Matrix. Data yang digunakan berjumlah 200 data tweet terdiri dari 100 komentar positif dan 100 komentar negatif menggunakan lima rasio perbandingan data latih dan data uji. Penelitian menghasilkan evaluasi tertinggi pada pada 8-Fold Cross Validation dengan accuracy sebesar $86,00 \%$, precision sebesar $87,38 \%$, dan recall sebesar $85,02 \%$ [2].

Bahkan terdapat pula beberapa penelitian tentang analisis sentimen sebelumnya yang membahas terkait cyberbullying pada beberapa platform media sosial seperti dalam penelitian yang dilakukan pada tahun 2018 oleh Wanda Athira Luqyana, dkk. Yang berjudul analisis sentimen cyberbullying pada komentar instagram dengan metode klasifikasi Support Vector Machine, dengan melakukan uji coba pada dokumen yang berisi 400 data yang diambil secara luring (offline) dengan total fitur 1799. Dokumen komentar dibagi menjadi 70\% data latih dan $30 \%$ data uji. Berdasarkan pengujian yang dilakukan didapatkan parameter terbaik pada metode SVM yaitu dengan nilai degree kernel polynomial sebesar 2, nilai learning rate sebesar 0,0001, dan jumlah iterasi maksimum yang digunakan adalah 200 kali. Dari pengujian tersebut didapatkan hasil akurasi tertinggi sebesar 90\% pada komposisi data latih 50\% dan komposisi data uji 50\% [3].

Pada tahun 2020 juga, Fajar Agus Maulana dan Iin Ernawati melakukan penelitian terkait analisis sentimen cyberbullying ini dengan memanfaatkan media sosial twitter dan menggunakan algoritma Naive Bayes Classifier. Hasil pengujian dengan data uji real time pada tanggal 12 Mei 2020 pukul 01.00 WIB mendapatkan nilai akurasi sebesar 76\%. Metode ini cukup baik dalam mengklasifikasikan tweet positif dan negatif, namun pada proses pengujian penelitian ini dalam mendeteksi tweet yang mengandung unsur cyberbullying masih kurang baik, dikarenakan masih terdapatnya tweet yang tidak mengandung unsur cyber bullying didalam data latih yang memiliki label tweet negatif [4].
Dari penelitian-penelitian terkait analisis sentimen yang pernah dilakukan seperti pada contoh diatas, diketahui bahwa terdapat beberapa metode yang dapat digunakan untuk melakukan analisis sentimen ini seperti Naive Bayes Classifier dan Support Vector Machine yang dimana jika dilihat dari hasil penelitian yang dilakukan, terdapat perbedaan tingkat akurasi dari hasil pemodelan dengan kedua sistem tersebut.

Terkait hal tersebut, Nurrun Muchammad Shiddieqy, dkk. Melakukan penelitian studi literatur tentang perbandingan metode untuk proses analisis sentimen di twitter, dimana dalam penelitian tersebut mereka membandingkan beberapa hasil penelitian yang dilakukan sebelumnya dimana perbandingan dua metode yang bisa digunakan untuk melakukan proses analisis sentimen disertai tahapan yang akan dilalui. Metode yang dibandingkan adalah Naive Bayes Classifier dan Support Vector Machine. Dari hasil studi literatur ini dapat disimpulkan dan bisa dilihat bahwa hasil terbaik dapat diraih menggunakan metode Support Vector Machine. Namun, untuk tetap mendapatkan hasil klasifikasi terbaik, maka lebih baik dilakukan pengujian yang bersifat komparatif dengan beberapa metode klasifikasi pada penelitian yang sedang dilakukan [5].

\subsection{Dasar Teori}

\subsubsection{Analisis Sentiment}

Analisis Sentimen adalah klasifikasi dari opini dan sentimen yang diungkapkan dalam teks, yang dihasilkan oleh manusia melalui teknologi Data Mining. Analisis Sentimen menyediakan fitur ekstraksi otomatis dan kemampuan representasi dan kinerja yang lebih baik daripada teknik berbasis fitur tradisional [6]. Analisis Sentimen ditujukan untuk mencari pendapat orang lain. Ini tidak hanya berlaku untuk individu tetapi juga berlaku untuk organisasi. Contohnya saat ini, jika seseorang ingin membeli produk konsumen, tidak lagi terbatas untuk meminta pendapat teman dan keluarga seseorang karena ada banyak ulasan pengguna dan diskusi tentang produk di forum publik di website. Bagi sebuah organisasi, mungkin tidak perlu lagi melakukan survei, jajak pendapat, dan memfokuskan diri untuk mengumpulkan opini publik. Beberapa tahun terakhir, postingan pendapat di media sosial juga telah membantu membentuk bisnis, mempengaruhi sentimen publik dan emosi publik [7].

\subsubsection{Cyberbullying}

Cyberbullying dapat diartikan sebagai teknologi internet untuk menyakiti orang lain dengan cara sengaja dan diulang-ulang. Cyberbullying adalah bentuk intimidasi yang pelaku lakukan untuk melecehkan korbannya melalui perangkat teknologi. Korban yang mengalami Cyberbullying akan melibatkan gangguan fisik hingga psikologis seperti kesepian, kegelisahan, depresi yang lebih tinggi, dan merasa hargadirinya rendah. Selain itu korban yang 
mengalami Cyberbullying juga akan merasakan tekanan sehingga menunjukkan keinginan bunuh diri yang lebih tinggi [8].

\subsubsection{Text Preprocessing}

Text Preprocessing merupakan tahap awal dari text mining untuk mengubah data sesuai dengan format yang dibutuhkan. Proses ini dilakukan untuk menggali, mengolah dan mengatur infomasi dan untuk menganalisis hubungan tekstual dari data terstruktur dan data tidak terstruktur [9]. Proses preprocessing juga bertujuan agar data yang digunakan memiliki dimensi yang lebih kecil dan terstruktur, sehingga dapat diolah lebih lanjut. Tahapan dari preprocessing meliputi: case folding, cleansing, normalisasi bahasa, convert negation, stopwords removal, tokenizing.

\subsubsection{Pembobotan TF-IDF}

Algoritma TF-IDF (Term Frequency Inverse Document Frequency) adalah salah satu algoritma yang dapat digunakan untuk menganalisa hubungan antara sebuah frase/kalimat dengan sekumpulan dokumen.

1. Term Frequency (TF)

TF (Term Frequency) adalah frekuensi dari kemunculan sebuah term dalam dokumen yang bersangkutan. Semakin besar jumlah kemunculan suatu term (TF tinggi) dalam dokumen, semakin besar pula bobotnya atau akan memberikan nilai kesesuaian yang semakin besar. Term Frequency (TF) dapat diformulakan seperti pada persamaan (2.1) berikut ini:

$$
T F=1+\log \left(F_{t, d}\right), F_{\mathrm{t}, d}>0
$$

Dimana nilai $F_{\mathrm{t} \text { d }}$ adalah frekuensi term (t) pada document (d). Jadi jika suatu kata atau term terdapat dalam suatu dokumen sebanyak 5 kali maka diperoleh bobot $=1+\log (5)=1.699$. Tetapi jika term tidak terdapat dalam dokumen tersebut, bobotnya adalah nol (0).

2. Inverse Document Frequency (IDF)

IDF (Inverse Document Frequency) merupakan sebuah perhitungan dari bagaimana term didistribusikan secara luas pada koleksi dokumen yang bersangkutan. IDF menunjukkan hubungan ketersediaan sebuah term dalam seluruh dokumen. Semakin sedikit jumlah dokumen yang mengandung term yang dimaksud, maka nilai IDF semakin besar.Sedangkan untuk Inverse Document Frequency (IDF) dihitung dengan menggunakan formula seperti pada persamaan (2.2) sebagai berikut:

$$
I D F=\log (D / d f)
$$

Dimana D adalah jumlah semua dokumen dalam koleksi sedangkan dfj adalah jumlah dokumen yang mengandung term $(\mathrm{t} \mathrm{j})$.

Jenis formula TF yang biasa digunakan untuk perhitungan adalah TF murni (raw TF). Dengan demikian rumus umum untuk Term Weighting TF-
IDF adalah penggabungan dari formula perhitungan raw TF dengan formula IDF dengan cara mengalikan nilai TF dengan nilai IDF seperti pada persamaan (2.3) dibawah ini : [10].

$$
W=t f x i d f
$$

\subsubsection{Support Vector Machine}

Support Vector Machine (SVM) adalah suatu teknik untuk melakukan suatu prediksi, baik dalam kasus klasifikasi atau regresi. Metode SVM memiliki prinsip dasar linier classifier yaitu kasus klasifikasi yang dapat dipisahkan seara linier, namun SVM yang dikembangkan dapat bekerja dengan problem nonlinier dengan memasukkan konsep kernel pada ruang berdimensi tinggi. Pada ruang berdimensi tinggi, hyperplane yang akan dapat memaksimalkan jarak(margin) antara kelas data. Metode Support Vector Machine (SVM) berakar dari teori pembelajaran statistik yang dapat memberikan hasil yang lebih baik dari metode yang lain.

SVM dapat bekerja dengan data pada non linier dengan menggunakan pendekatan kernel pada fitur awal himpunan data. Fungsi kernel yang digunakan untuk memetakan dimensi awal (dimensi yang lebih rendah) himpunan data ke dimensi baru (dimensi yang lebih tinggi). Konsep SVM adalah pencarian hyperplane terbaik yang berfungsi sebagai pemisah data dari dua kelas pada input space. Hyperplane pemisah terbaik adalah hyperplane yang terletak di tengah diantara dua set objek dari dua kelas. Hyperplane terbaik dapat dicari dengan memaksimalkan margin atau jarak dari dua set objek dari dua kelas yang berbeda. Dapat diasumsikan bahwa kedua belah kelas dapat terpisah secara sempurna oleh hyperplane(linear separable). Akan tetapi, pada umumnya dua belah kelas pada input space tidak dapat terpisah secara sempurna(non linear separable). Untuk mengatasi masalah ini SVM dirumuskan ulang dengan memperkenalkan metode margin[2]. Seperti pada Gambar 1.

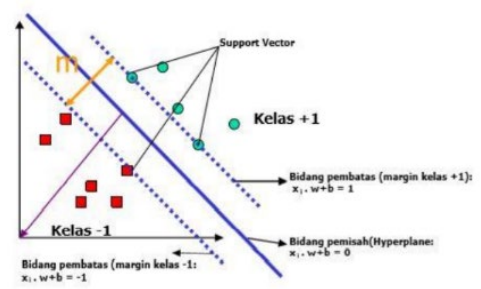

Gambar 1. Margin Hyperplane

\subsubsection{Evaluasi Klasifikasi}

Evaluasi merupakan tahapan terakhir dalam setiap data mining dan klasifikasi teks. Pada tahap ini akan mengevaluasi hasil percobaan, membandingkan dan menganalisis terhadap kinerja klasifikasi teks. Pada penelitian ini evaluasi yang adalah perhitungan Recall, Precision, specificity dan accuracy. Nilai pada semua perhitungan tersebut didasarkan pada hasil confusion matrix yang didapatkan setelah 
melakukan pengujian model dan data testing. Confusion matrix dapat dilihat pada tabel 2.1.

Tabel 1. Tabel Confusion Matrix

\begin{tabular}{|c|l|l|}
\hline Predicted & \multicolumn{2}{|c|}{ True Class } \\
\cline { 2 - 3 } Class & \multicolumn{1}{|c|}{ Positif } & Negatif \\
\hline Positif & True Positif (TP) & False Positif (FP) \\
\hline Negatif & False Negatif (FN) & True Negatif (TN) \\
\hline
\end{tabular}

Keempat parameter diatas digunakan untuk menghitung 3 metode evaluasi yakni:

1. Recall, yaitu perbandingan jumlah dokumen yang relevan terkenali dengan jumlah seluruh dokumen relevan. Recall memiliki rumusan seperti pada persamaan (2.4).

$$
\text { Recall }=\frac{T P}{T P+F P} \times 100 \%
$$

2. Precision, yaitu perbandingan jumlah dokumen yang relevan terkenali dengan jumlah dokumen yang terkenali. Precision memiliki rumusan seperti pada persamaan (2.5).

$$
\text { Precision }=\frac{T P}{T P+F N} \times 100 \%
$$

3. Accuracy, yaitu seberapa akurat sistem dapat menklasifikasikan secara benar. Accuracy memiliki rumusan seperti pada persamaan (2.6).

$$
\text { Accuracy }=\frac{T N+T P}{T N+T P+F N+F P} \times 100 \%
$$

Nilai recall, precision dan accuracy dinyatakan dalam persen. Semakin tinggi persentase ketiga nilai tersebut menunjukan semakin baik kinerja sistem klasifikasi teks otomatis.

\section{METODE PENELITIAN}

\subsection{Analisis Sistem}

Dalam pengembangan sistem analisis sentimen cyberbullying di twitter ini user akan melakukan crawling data dari twitter untuk mendapatkan dataset berupa konten tweet yang mengandung abusive word dan berpotensi menjadi konten cyberbullying dengan maksimal data tidak lebih dari 100 tweets Bahasa Indonesia dalam rentang waktu 7 hari terakhir sejak pengambilan data. Setelah dataset didapatkan, makan selanjutnya akan dilakukan proses text preprocessing, adapun tahapan preprocessing yang akan dilakukan pada penelitian ini yaitu Case folding, Cleansing, Normalisasi Bahasa, Convert Negation, Stopword Removal, Tokenisasi.

Sistem yang akan dibuat berbasis web dengan menggunakan metode klasisfikasi dari Sentiment Analylis dengan algoritma Support Vector machine (SVM) akan menampilkan hasil klasifikasi sentiment dari setiap tweet dalam dataset yang dimasukkan. Sehingga dengan adanya sistem ini nantinya diharapkan dapat membantu kinerja polisi virtual POLRI ini dalam mengidentifikasi tweet yang berpotensi melanggar pidana UU ITE tersebut dan secara tidak langsung akan meminimalisir pengguna untuk membuat konten Twitter yang mengandung unsur cyberbullying.

\subsection{Blok Diagram Sistem}

Dalam blok diagram sistem, menunjukkan bagaimana alur dari sistem akan berjalan mulai dari input apa saja yang akan diberikan kemudian proses yang dilakukan sampai output hasil akhir yang akan diberikan. Bisa dilihat pada gambar diagram 2.

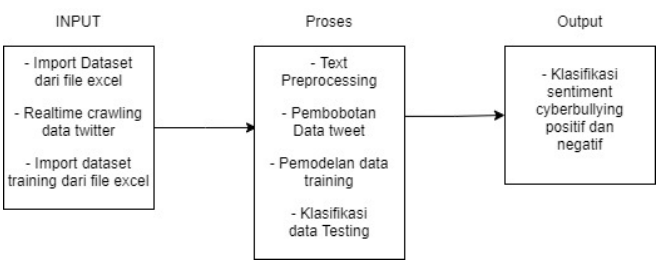

Gambar 2. Blok diagram system

\subsection{Desain Arsitektur Sistem}

Sistem ini dimulai dengan melakukan crawling data secara otomatis menggunakan twitter API untuk mendapatkan data collection atau dataset tweets dengan dalam Bahasa Indonesia. Sebelum melakukan tahap klasifikasi dilakukan tahap teks preprocessing yakni proses reduksi teks yang bertujuan membuang kata-kata atau term-term yang tidak memiliki kontribusi atau bobot yang mempengaruhi tahap selanjutnya.

Data yang telah melaui tahapan Preprocessing telah siap untuk diolah. Pada data mentah tersebut akan dilakukan proses pembobotan pada setiap kata (term) dan memberikan hasil akhir berupa bobot TFIDF. Hasil dari pembobotan ini yang akan digunakan dalam proses klasifikasi dengan metode SVM. Output dari sistem ini merupakan data dengan nilai ouput positif atau negatif yang diklasifikasikan oleh sistem berdasarkan nilai probabilitas yang ada. Flowchart desain arsitektur sistem ini dapat dilihat pada gambar 3.

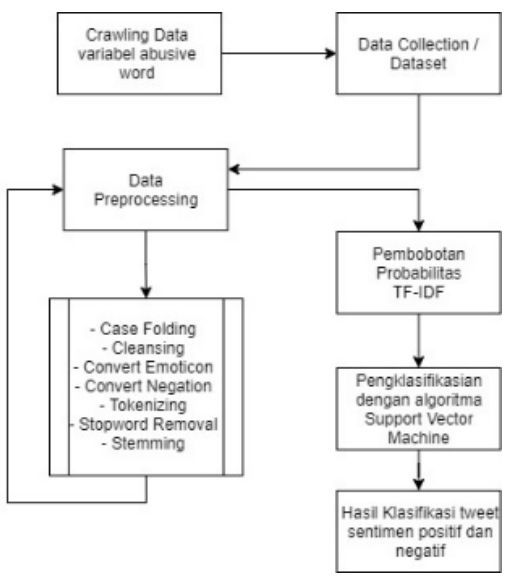

Gambar 3. Desain Arsitektur Sistem

\subsection{Pemodelan Proses Text Preprocessing}

Sebelum melakukan proses klasifikasi sentiment cyberbullying dilakukan proses text preprocessing terlebih dahulu yakni proses reduksi teks yang bertujuan membuang kata-kata atau term-term yang tidak memiliki kontribusi atau bobot yang 
mempengaruhi tahap selanjutnya. Proses text preprocessing yang dilakukan diantaranya yakni casefolding, cleansing, normalization, stopword removal, convert negation, stemming, dan tokenizing, akan menghasilkan query term yang akan digunakan pada tahap selanjutnya. Proses ini digunakan untuk mengurangi atribut yang kurang berpengaruh terhadap proses klasifikasi. Data yang dimasukkan pada tahap ini masih berupa data mentah. Proses text preprocessing terdiri dari beberapa tahap yang dapat dilihat pada gambar 4 .

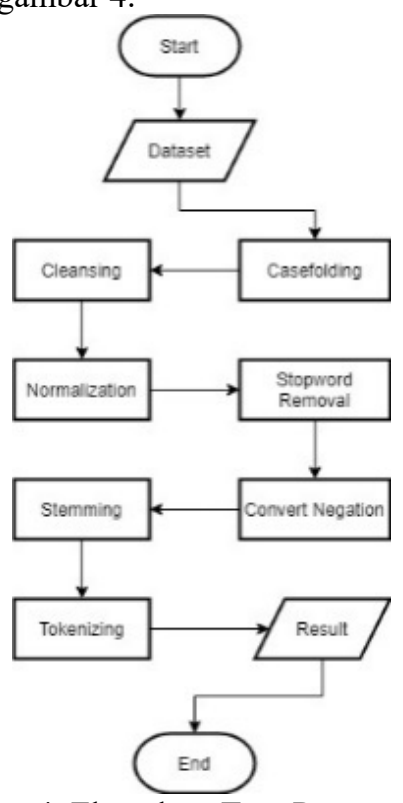

Gambar 4. Flowchart Text Preprocessing

\subsection{Pemodelan Proses Pembobotan TF-IDF}

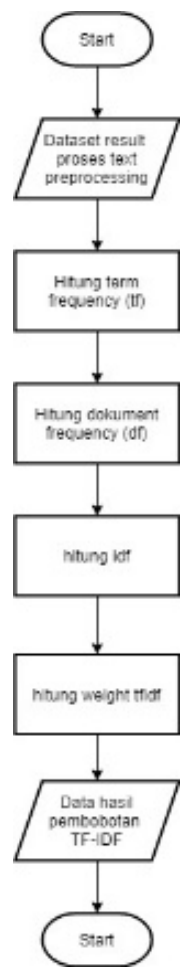

Gambar 5. Flowchart Pembobotan TF-IDF
Pada penelitian ini pembobotan diperoleh dari frekuensi sebuah kata yang terdapat di dalam dokumen tweet atau jumlah kemunculan term dalam satu dokumen term frequency (tf) yang dapat dihitung dengan persamaan (2.1) dan sebuah kata di dalam kumpulan dokumen atau jumlah kemunculan term dalam koleksi dokumen inverse document frequency (idf). Nilai idf sebuah term (kata) dapat dihitung menggunakan persamaan (2.2). Untuk menghitung bobot (W) masing-masing dokumen terhadap setiap term (kata) dapat menggunakan persamaan (2.3). Adapun flowchart dari proses pembobotan tf-idf dapat dilihat pada Gambar 5 .

\subsection{Pemodelan Proses Support Vector Machine}

Data pada ruang input (input space) berdimensi d dinotasikan dengan $x_{i}=\in \Re^{d}$ sedangkan label kelas dinotasikan dengan $y_{i} \in\{-1,+1\}$ untuk $i=1$, $2, \ldots, n$. Dimana $\mathrm{n}$ adalah banyaknya data. Untuk mencari nilai $x_{i}$ dan $y_{i}$ dapat dilakukan ketika sudah didapatkan nilai tiap kata (term) dari pembobotan tfidf dan label tweet dari anotator. Hasil dari pembobotan tf-id diubah ke dalam bentuk format data svm light, sedangkan hasil pelabelan dari anotator menjadi label data svm.

Untuk mendapatkan nilai $a_{i}$, langkah pertama adalah mengubah setiap kalimat menjadi nilai vektor (support vector) $=\left[\begin{array}{l}X \\ Y\end{array}\right]$. Kemudian nilai vektor dari setiap kalimat dimasukkan ke persamaan (3.6) kernel trick phi berikut:

$$
D_{i}=\varnothing\left[\begin{array}{l}
x \\
y
\end{array}\right]=\left[\begin{array}{l}
\sqrt{x_{n}^{2}+y_{n}^{2}}-x+(x-y)^{2} \\
\sqrt{x_{n}^{2}+y_{n}^{2}}-y+(x-y)^{2}
\end{array}\right]
$$

Nilai x didapatkan dari persamaan (3.7) kernel linear untuk $\mathrm{x}$ berikut:

$$
\sum_{i=1, j=1}^{1} x_{i} x_{j}^{T},(i, j=1, \ldots, n)
$$

Nilai y didapatkan dari persamaan (3.8) kernel linear untuk y berikut:

$\sum_{i=1, j=1}^{1} y_{i} y_{j}^{T},(i, j=1, \ldots, n)$

Untuk mendapatkan jarak tegak lurus yang optimal dengan mempertimbangkan vektor positif, maka hasil perhitungan dari substitusi nilai $\mathrm{x}$ dan nilai $\mathrm{y}$ ke persamaan (3.6) diberi nilai bias $=1$. Kemudian cari parameter $a_{\mathrm{i}}$, dengan terlebih dahulu mencari nilai fungsi setiap kalimat menggunakan persamaan (3.9), lalu mencari nilai $a_{\mathfrak{i}}$ pada persamaan linear menggunakan persamaan (3.10) dengan memperhatikan $i_{s} j=1_{, \ldots,} n$ berikut :

$$
\begin{aligned}
& \sum_{i=1, j=1}^{1} a_{i} D_{i}^{T} D_{j} \\
& \sum_{i=1, j=1}^{1} a_{i} D_{i}^{T} D_{j}=y_{i}
\end{aligned}
$$

Setelah parameter $a_{\mathfrak{i}}$ didapatkan, kemudian masukkan ke persamaan (3.11) berikut :

$\widetilde{W}=\sum_{i=1}^{n} a_{i} D_{i}$

Hasil yang didapatkan menggunakan persamaan (3.11), selanjutnya digunakan persamaan (3.12) untuk mendapatkan nilai $\mathrm{w}$ dan $\mathrm{b}$ :

$$
y=w \cdot x+b
$$


Sedemikian sehingga didapatkanlah nilai $\mathrm{w}$ dan nilai $b$ atau nilai hyperplane untuk mengklasifikasikan kedua kelas. Untuk alur pemodelan metode support vector machine ini didalam sistem dapat dilihat pada gambar 6 .

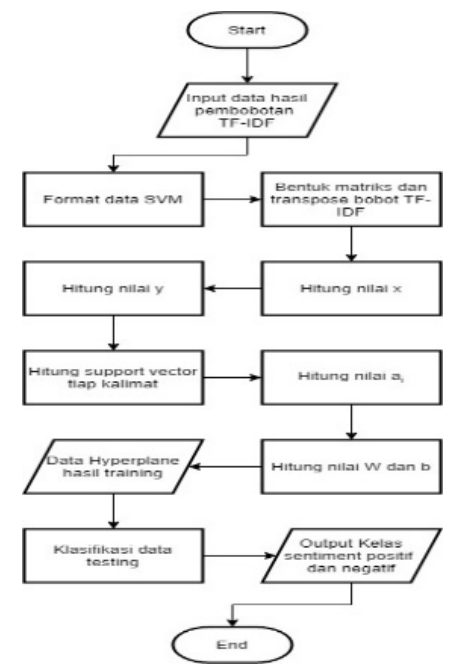

Gambar 6. Flowchart Metode SVM

\section{HASIL DAN PEMBAHASAN}

\subsection{Implemntasi Sistem}

Sistem ini diimplementasikan pada platform web browser menggunakan bahasa pemrograman PHP dan didesain dengan menggunakan HTML, CSS dan Javascript serta menggunakan MySQL sebagai Database Management system. Dalam proses implementasi, akan digunakan 100 data testing yang sudah didapatkan dalam proses crawling baik realtime maupun dalam dataset spreadsheet excel. Untuk data training digunakan dataset dari spreadsheet excel yang telah diberikan label sentiment cyberbullyinng positif dan negatif oleh anotator sebanyak 150 data tweet.

\subsection{Halaman Import Data Train}

Pada halaman import dataset training ini disajikan tombol import dataset yang dapat digunakan user untuk menginputkan dataset tweet yang berupa file spreadsheet excel yang telah diberikan label sentimen cyberbyllying positif dan negatif pada masing-masing tweet pada dataset oleh anotator. Halaman import dataset training dapat dilihat pada gambar 7 .

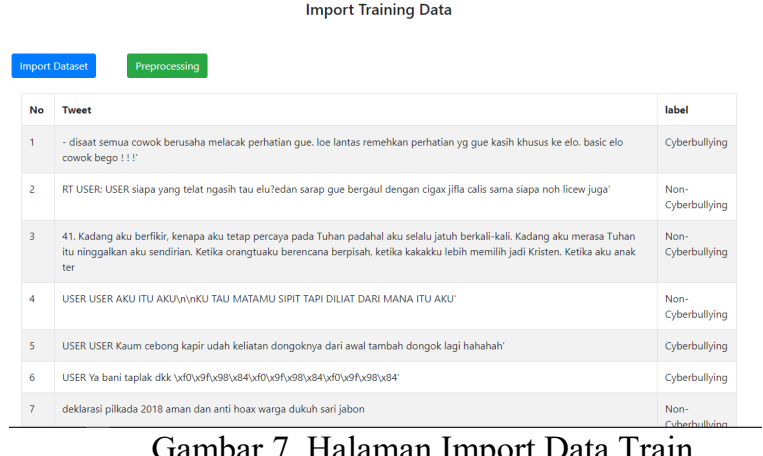

\subsection{Halaman Import Data Testing}

Pada halaman import dataset testing ini disajikan tombol import dataset yang dapat digunakan user untuk menginputkan dataset tweet yang berupa file spreadsheet excel yang didapatkan melalui proses crawling dengan tools. Halaman import dataset testing dapat dilihat pada gambar 8 .

$$
\text { Import Dataset }
$$

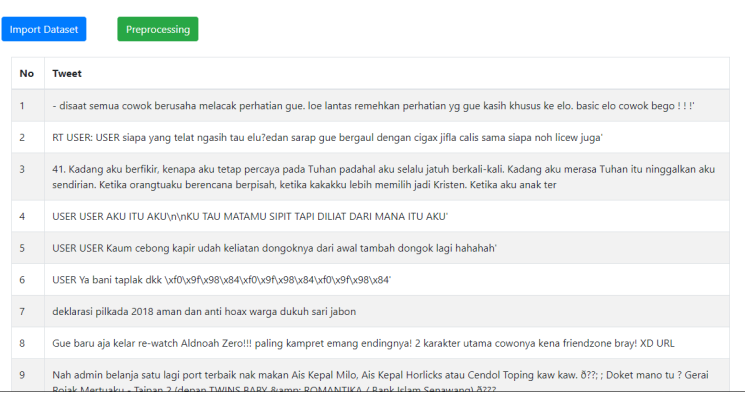

Gambar 8. Halaman Import Data Testing

\subsection{Halaman Realtime Crawling}

Pada halaman realtime crawling ini disajikan tombol crawling yang dapat digunakan user untuk melakukan crawling data twitter secara realtime dengan menginputkan query tertentu. Realtime crawling data twitter ini memanfaatkan akses dari twiiter API untuk mendapatkan data berdasarkan query yang diinputkan. Halaman realtime crawling dapat dilihat pada gambar 9 .

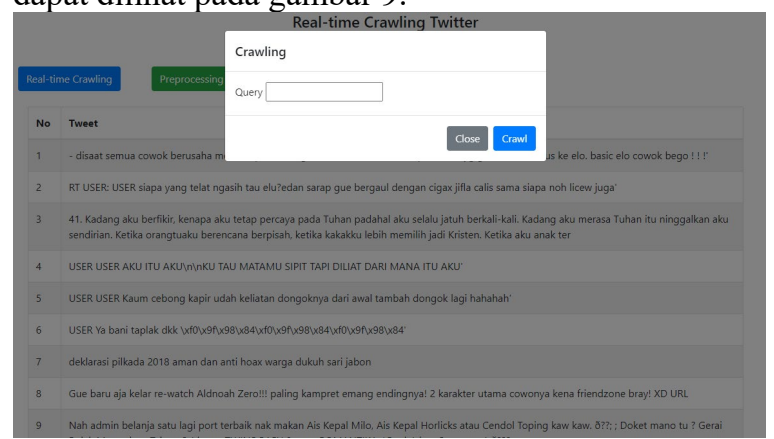

Gambar 9. Halaman Realtime Crawling

\subsection{Halaman Text Preprocessing}

Pada halaman text preprocerssing ini diajikan tombol untuk melakukan proses text preprocessing pada dataset training yang telah diinpuitkan pada halaman sebelumnya. Pada proses text preprocessing ini dilakukan beberapa tahap yang telah disebutkan pada analisis dan perancangan sistem sebelumnya. Setelah proses selesai maka data hasil akan ditampilkan pada table halaman text preprocessing. Halaman text preprocessing dapat dilihat pada gambar 10. 


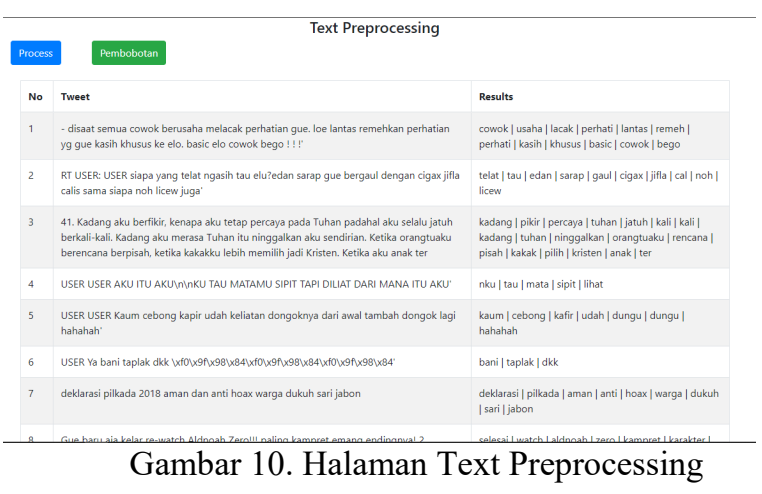

4.6. Halaman Pembobotan TF-IDF

Pada halaman pembobotan disajikan tombol untuk melakukan proses perhitungan TF (Term Frequency) dan tombol untuk melakukan proses perhitungan TF-IDF (Term Frequency - Inverse Document Frequency) dari data yang telah melewati proses text preprocessing dan terpecah menjadi kumpulan term atau kata. Setelah perhitungan masing-masing proses selesai maka data hasil pembobotan akan ditampilkan pada tabel halaman pembobotan ini. Halaman pembobotan data testing dapat dilihat pada gambar 11 .

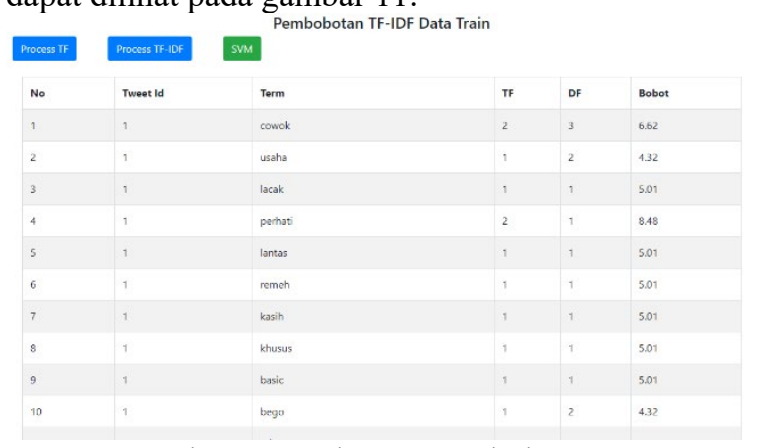

Gambar 11. Halaman Pembobotan TF-IDF

\subsection{Halaman Klasifikasi Sentiment}

Pada halaman klasifikasi sentiment ini terdapat tombol yang digunakan untuk melakukan proses metode support vector machine. Dimulai dengan melakukan proses training pada data training untuk membentuk model klasifikasi dan mendapatkan hyperplane yang kemudian digunakan sebagai acuan dalam melakukan proses klasifikasi data tweet testing yang diberikan. Setelah proses berhasil dilakukan maka hasil klasifikasi sentiment cyberbullying dari data tweet testing yang didapatkan akan ditampilkan pada tabel halaman Klasifikasi sentiment seperti yang dapat dilihat pada gambar 12 . Hasil perhitungan klasifikasi sentiment berupa label yaitu -1 dan 1. Jika label hasil perhitungan klasifikasi adalah -1 maka tweet tersebut merupakan sentiment cyberbullying negatif atau tweet non-cyberbullying, sebaliknya jika label yang diberikan adalah 1 maka tweet tersebut merupakan sentiment cyberbullying positif atau tweet cyberbullying.

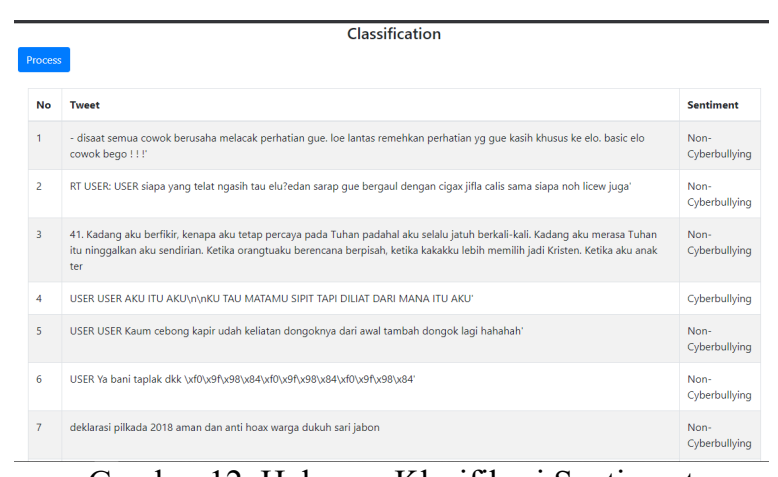

Gambar 12. Halaman Klasifikasi Sentiment

\subsection{Pengujian Kecepatan Sistem untuk Klasifikasi}

Kecepeatan suatu sistem dapat diukur dengan menemukan nilai kecepatan rata-rata sistem saat mengeksekusi program. Sehingga dalam penelitian ini, untuk mengukur kecepatan algoritma support vector machine, sistem akan menjalankan tiga skenario eksekusi program dengan jumlah data tiap eksekusi yang berbeda. Skenario pertama akan mengeksekusi program dengan 33 data, skenario kedua menggunakan 66 data dan skenario ketiga menggunakan 100 data. Masing-masing skenario akan dijalankan sebanyak 10 kali dan menghitung rata-rata waktu yang dihabiskan untuk memproses data tersebut.

\section{Pengujian kecepatan dengan 33 data}

Tabel 1. Pengujian Kecepatan dengan 33 data

\begin{tabular}{|c|c|}
\hline Trial & Waktu \\
\hline 1 & 11986 \\
\hline 2 & 10083 \\
\hline 3 & 7972 \\
\hline 4 & 8756 \\
\hline 5 & 10867 \\
\hline 6 & 8884 \\
\hline 7 & 10158 \\
\hline 8 & 8862 \\
\hline 9 & 9089 \\
\hline 10 & 9528 \\
\hline
\end{tabular}

Dengan data hasil pengujian skenario pertama yang menggunakan 33 data dan percobaan sebanyak 10 kali maka dilakukanlah perhitungan rata-rata waktu dan kecepatan proses dengan hasil bahwa untuk memproses 33 data, sistem membutuhkan ratarata waktu $9618,5 \mathrm{~ms}$ dan kecepatan pemrosesan data 0,003431 data per milisecond.

\section{Pengujian Kecepatan dengan 66 data}

Tabel 2. Pengujian Kecepatan dengan 66 data

\begin{tabular}{|c|c|}
\hline Trial & Waktu \\
\hline 1 & 127301 \\
\hline 2 & 122393 \\
\hline 3 & 136345 \\
\hline 4 & 140396 \\
\hline 5 & 105337 \\
\hline 6 & 133466 \\
\hline 7 & 120520 \\
\hline 8 & 138192 \\
\hline 9 & 57663 \\
\hline 10 & 136604 \\
\hline
\end{tabular}


Dengan data hasil pengujian skenario kedua yang menggunakan 66 data dan percobaan sebanyak 10 kali maka dilakukanlah perhitungan rata-rata waktu dan kecepatan proses dengan hasil bahwa untuk memproses 66 data, sistem membutuhkan ratarata waktu $121821,7 \mathrm{~ms}$ dan kecepatan pemrosesan data 0,000542 data per milisecond.

\section{Pengujian Kecepatan dengan 100 data}

Tabel 3. Pengujian Kecepatan dengan 100 data

\begin{tabular}{|c|c|}
\hline Trial & Waktu \\
\hline 1 & 122037 \\
\hline 2 & 139617 \\
\hline 3 & 107951 \\
\hline 4 & 113102 \\
\hline 5 & 42310 \\
\hline 6 & 116324 \\
\hline 7 & 108801 \\
\hline 8 & 108396 \\
\hline 9 & 49035 \\
\hline 10 & 103429 \\
\hline
\end{tabular}

Dengan data hasil pengujian skenario pertama yang menggunakan 100 data dan percobaan sebanyak 10 kali maka dilakukanlah perhitungan rata-rata waktu dan kecepatan proses dengan hasil bahwa untuk memproses 100 data, sistem membutuhkan rata-rata waktu 101100,2 ms dan kecepatan pemrosesan data 0,000989 data per milisecond.

\subsection{Pengujian Evaluasi Klasifikasi}

Pengujian evaluasi klasifikasi bertujuan untuk mengecek kebenaran hasil klasifikasi dengan menghitung berapa angka yang diperoleh. Acuan yang dipakai untuk tahap evaluasi klasifikasi ini yakni perhitungan tabel confussion matrix. Dalam pengujian ini dilakukan dua skenario yaitu seknario 1 dengan 100 data train dan skenario 2 dengan 200 data train. Dengan data test dari dokumen tweet sebanyak 100 dokumen yang telah didapatkan dengan perbandingan label dari anotator dan label yang didapatkan dari proses pada sistem yang dapat dilihat pada tabel 4. dan 5 .

Tabel 4. Perhitungan Confusion Matrix Skenario 1

\begin{tabular}{|l|l|l|l|}
\hline \multirow{2}{*}{$\begin{array}{l}\text { Predicted } \\
\text { Class }\end{array}$} & \multicolumn{2}{|l|}{ True Class } & \multirow{2}{*}{ Total } \\
\cline { 2 - 3 } & Positif & Negatif & 36 \\
\hline Positif & 23 & 13 & 64 \\
\hline Negatif & 17 & 47 & 100 \\
\hline Total & 40 & 60 & 1 \\
\hline
\end{tabular}

Setelah melakukan perhitungan confusion matrix maka didapatkanlah nilai-nilai yang akan digunakan dalam proses perhitungan recall dengan persamaan (2.4), precison dengan persamaan (2.5) dan accuracy dengan persamaan (2.6). Berikut perhitungan untuk masing evaluasi yang dilakukan:

$$
\begin{aligned}
& \text { Recall }=\frac{T P}{T P+F P} \times 100 \%=\frac{23}{23+13} \times 100 \%=64 \% \\
& \text { Precision }=\frac{T P}{T P+F N} \times 100 \%=\frac{23}{23+17} \times 100 \%=58 \%
\end{aligned}
$$

$A c c u r a c y=\frac{T N+T P}{T N+T P+F N+F P} \times 100 \%=\frac{47+23}{47+23+17+13} \times 100 \%=70 \%$

Berdsarkan tabel 4., diperoleh dokumen dengan prediksi positif dan faktanya positif sebanyak 23 tweet, dokumen dengan prediksi positif dan faktanya negatif sebanyak 13 tweet, dokumen dengan prediksi negatif dan faktanya negatif sebanyak 47 tweet, serta dokumen dengan prediksi negatif dan faktanya positif sebanyak 17 tweet. Berdasarkan hasil perhitungan evaluasi rata-rata akurasi dengan dokumen sebanyak 100 tweet diperoleh hasil recall $64 \%$, precission $58 \%$, dan accuracy sebesar $70 \%$.

Tabel 5. Perhitungan Confusion Matrix Skenario 2

\begin{tabular}{|l|l|l|l|}
\hline \multirow{2}{*}{$\begin{array}{c}\text { Predicted } \\
\text { Class }\end{array}$} & \multicolumn{2}{|l|}{ True Class } & Total \\
\cline { 2 - 4 } & Positif & Negatif & \\
\hline Positif & 25 & 10 & 35 \\
\hline Negatif & 15 & 50 & 65 \\
\hline Total & 40 & 60 & 100 \\
\hline
\end{tabular}

Setelah melakukan perhitungan confusion matrix maka didapatkanlah nilai-nilai yang akan digunakan dalam proses perhitungan recall dengan persamaan (2.4), precison dengan persamaan (2.5) dan accuracy dengan persamaan (2.6). Berikut perhitungan untuk masing evaluasi yang dilakukan:

$$
\begin{aligned}
& \text { Recall }=\frac{T P}{T P+F P} \times 100 \%=\frac{25}{25+10} x 100 \%=71 \% \\
& \text { Precision }=\frac{T P}{T P+F N} \times 100 \%=\frac{25}{25+15} \times 100 \%=63 \% \\
& \text { Accuracy }=\frac{T N+T P}{T N+T P+F N+F P} \times 100 \%=\frac{50+25}{50+25+15+10} \times 100 \%=75 \%
\end{aligned}
$$

Berdsarkan tabel 4.5, diperoleh dokumen dengan prediksi positif dan faktanya positif sebanyak 25 tweet, dokumen dengan prediksi positif dan faktanya negatif sebanyak 10 tweet, dokumen dengan prediksi negatif dan faktanya negatif sebanyak 50 tweet, serta dokumen dengan prediksi negatif dan faktanya positif sebanyak 15 tweet. Berdasarkan hasil perhitungan evaluasi rata-rata akurasi dengan dokumen sebanyak 200 tweet diperoleh hasil recall $71 \%$, precission $63 \%$, dan accuracy sebesar $75 \%$.

Sistem analisis sentiment cyberbullying yang dibangun telah mampu mentransformasikan dan mengklasifikasikan sentiment cyberbullying yang berupa teks dari twitter dan menampilkan informasi berupa data konten tweet dan hasil klasifikasi tweet tersebut apakah mengandung unsur cyberbullying atau non-cyberbullying. Tingkat keakuratan yang dihasilkan dengan menggunakan metode support vector machine mencapai nilai $70 \%$ sehingga dapat dikatakan metode ini dapat digunakan sebagai metode analisis sentiment yang baik. Tingkat akurasi akan semakin baik bila data latih yang digunakan lebih banyak.

\section{KESIMPULAN DAN SARAN \\ 5.1. Kesimpulan}

Berdasarkan hasil penelitian terkait analisis sentiment cyberbullying pada media sosial twitter menggunakan metode support vector machine ini maka dapat disimpulkan bahwa: 
1. Berdasarkan hasil dari pengujian blackbox testing menunjukkan bahwa sistem yang dibangun telah mampu mentransformasi dan mengklasifikasikan konten tweet yang mengandung unsur cyberbullying dan non-cyberbullying didalamnya.

2. Penggunaan metode support vector machine pada penelitian telah mampu melakukan klasifikasi dengan baik.

3. Penggunaan 100 data dokumen tweet untuk melakukan training dan membentuk model klasifikasi menghasilkan nilai recall $64 \%$, precision 58\% dan tingkat accuracy sebesar 70\%

4. Penggunaan 200 data dokumen tweet untuk melakukan training dan membentuk model klasifikasi menghasilkan nilai recall $71 \%$, precision $63 \%$ dan tingkat accuracy sebesar $75 \%$.

5. Jumlah data training dan ketepatan proses text preprocessing dalam menghilangkan dan membersihkan noise dokumen tweet mempengaruhi tingkat akurasi dan kinerja klasifikasi sentimen cyberbullying menggunakan metode support vector machine ini.

6. Hasil dari penelitian ini juga dapat digunakan untuk mengedukasi masyarakat khususnya pengguna twitter agar lebih mempertimbangkan konten opini tweet maupun komentar yang mereka tuliskan saat menggunakan media sosial.

\subsection{Saran}

Berdasarkan penelitian yang telah dilakukan, maka penulis dapat memberikan saran-saran untuk pengembangan selanjutnya antara lain:

1. Menambah jumlah data training yang digunakan untuk membentuk model klasifikasi agar tingkat akurasi yang didapatkan lebih tinggi.

2. Meningkatkan proses pembersihan dokumen tweet pada text preprocessing agar hasil lebih maksimal.

3. Menambahkan metode ekstraksi fitur lainnya agar mendapatkan bobot yang maksimal dan fitur yang tepat.

4. Meningkatkan kinerja algoritma support vector machine pada sistem agar waktu yang dibutuhkan untuk proses klasifikasi lebih cepat.

5. Sistem dapat dikembangkan untuk analisis sentiment dengan topik berbeda lainnya.

\section{DAFTAR PUSTAKA}

[1] Maria Mega Mala Olhang, Sentot Achmadi, F.X Ari Wibisono, 2020. Analisis Sentimen Pengguna Twitter Terhadap COVID-19 Di Indonesia Menggunakan Metode Naive Bayes
Classifier (NBC). JATI (Jurnal Mahasiswa Teknik Informatika) Vol. 4 No. 2 September 2020 Teknik Informatika ITN Malang.

[2] Amar P. Natasuwarna, 2020. Seleksi Fitur Support Vector Machine Pada Analisis Sentimen Keberlanjutan Pembelajaran Daring. Techno.COM Vol. 19 No. 4 November 2020: 437 - 448 Sistem informasi STMIK Pontianak.

[3] Wanda Athira Luqyana, Imam Cholissodin, Rizal Setya Perdana. 2018. Analisis Sentimen Cyberbullying pada Komentar Instagram dengan Metode Klasifikasi Support Vector Machine. Jurnal Pengembangan Teknologi Informasi dan Ilmu Komputer vol. 2 No. 11 November hlm. 4704-4713 e-ISSN: 2548-964X, Universitas Brawijaya.

[4] Fajar Agus Maulana, Iin Ernawati. 2020. Analisa Sentimen Cyberbullying di Jejaring Sosial Twitter dengan Algoritma Naive Bayes. Seminar Nasional Mahasiswa Ilmu Komputer dan Aplikasinya (SENAMIKA) ISBN 978-62393343-1-4, Jakarta-Indonesia.

[5] Nurrun Muchammad Shiddieqy Hadna, Paulus Insap Santosa, Wing Wahyu Winarno. 2016. Studi Literatur Tentang Perbandingan Metode Untuk Proses Analisis Sentimen Di Twitter. Seminar Nasional Teknologi Informasi dan Komunikasi 2016 (SENTIKA 2016) ISSN: 2089-9815, Yogyakarta.

[6] Araque, O. et al. 2017. Enhancing deep learning sentiment analysis with ensemble techniques in social applications. Expert Systems with Applications. Elsevier Ltd, 77, pp. 236-246. doi: 10.1016/j.eswa.2017.02.002.

[7] Zhang, L., Wang, S. and Liu, B. 2018. Deep learning for sentiment analysis: A survey, Wiley Interdisciplinary Reviews: Data Mining and Knowledge Discovery, 8(4), pp. 1-25. doi: 10.1002/widm. 1253.

[8] Kowalski, R. M. et al. (2016) 'Cyberbullying among college students with disabilities', Computers in Human Behavior. Elsevier Ltd, 57, pp. 416-427. doi: 10.1016/j.chb.2015.12.044.

[9] A. F. Hidayatullah and A. SN, "Analisis Sentimen Dan Klasifikasi Kategori Terhadap Tokoh Publik Pada Twitter," Seminar Nasional Informatika, vol.2 no.4, pp. 1-8, Okt 3,2015.

[10] https://informatikalogi.com/term-weighting-tf$\underline{\mathrm{idf} /}$, diakses tanggal 05 April 2021, pukul 13:00 WITA. 